\title{
Registros de representação semiótica em atividades de desenho geométrico no GeoGebra
}

\section{Registers of semiotic representations in geometrical drawing activities on GeoGebra}

Odalea Aparecida Viana

odalea@pontal.ufu.br

Carlos Eduardo Petronilho Boiago

carlosboiago@iftm.edu.br

\begin{abstract}
Resumo
O trabalho analisa as sequências utilizadas por alunos em atividades de desenho geométrico a partir de logotipos figurais. As construções, feitas no GeoGebra por estudantes do ensino médio, foram analisadas na perspectiva dos registros de representação semiótica de Raymond Duval. Foram identificadas as operações mereológicas de reconfiguração e de desconstrução dimensional. Considerou-se que o software permite interpretar e construir figuras envolvendo os diferentes tipos de apreensão em geometria e que as atividades de desenho possibilitam um melhor entendimento de alguns processos cognitivos específicos da atividade geométrica.
\end{abstract}

Palavras- chave: registros de representação semiótica; aprendizagem em geometria; apreensões em geometria; desenho geométrico; GeoGebra.

\begin{abstract}
This paper analyzes the sequences used by students in geometrical drawing activities based on figural logos. Constructions made on GeoGebra by high school students were analyzed in the perspective of Raymond Duval's registers of semiotic representation. Mereological operations of reconfiguration and dimensional deconstruction were identified. It was considered that software allows to interpret and construct figures involving different kinds of apprehensions in geometry and that drawing activities enable a better understanding of specific cognitive processes of geometrical activity.
\end{abstract}

Keywords: registers of semiotic representations; learning in geometry; apprehensions in geometry; geometrical drawing; GeoGebra.

\section{Introdução}

Entre as problemáticas existentes no processo de ensino e aprendizagem da geometria básica, destaca-se o desenho geométrico, ou seja, a construção de figuras geométricas no papel com o auxílio de instrumentos específicos, como régua graduada, compasso e transferidor. Uma das dificuldades refere-se ao conhecimento necessário para a realização dos procedimentos de desenho: se não dispuser de conceitos, a sequência de passos a serem memorizados para a 
construção de uma figura geométrica pode ser algo nada motivador para os alunos. Outra dificuldade é a própria instrumentação, ou seja, em um mundo digital em que vivem os alunos, pode parecer obsoleto utilizar papel, grafite e borracha, quando tantos softwares apresentam desenhos com precisão e acabamento bem mais interessantes.

Dificuldades no ensino e aprendizagem da geometria são amplamente apresentadas na literatura em educação matemática. No Brasil, muitos trabalhos tratam das questões referentes ao ensino básico e podem ser citados os que evidenciam a formação conceitual de alunos e professores dos anos iniciais do ensino fundamental, como o de Lamonato e Passos (2009), até os das séries finais do ensino médio, conforme pode ser visto em Proença e Pirola (2011), por exemplo. Alguns constataram que as construções geométricas com régua e compasso são pouco trabalhadas na escola básica, como os de Jucá (2011), Kopke (2006) e Zuin (2001).

Os Parâmetros Curriculares Nacionais (BRASIL, 1998), além de ponderarem que o trabalho inicial com figuras geométricas estimula o aluno a observar, perceber semelhanças e diferenças, identificar regularidades etc., também sugerem que o professor explore situações em que sejam necessárias algumas construções geométricas com régua e compasso: polígonos e seus elementos, retas paralelas e perpendiculares, ângulos, segmentos proporcionais, elementos do triângulo etc. No ensino médio, a habilidade de construção de figuras pode ser retomada, por exemplo, na planificação de poliedros - atividade que pode se tornar de "grande satisfação estética" (BRASIL, 2006, p. 93). Essas atividades seriam importantes na formação de conceitos, princípios e relações que caracterizam o chamado raciocínio geométrico dos estudantes.

Não se pode negar a existência de certo tipo de raciocínio quando se lida com objetos mentais que possuem simultaneamente propriedades conceptuais e figurativas, conforme ponderado por Fischbein (1978). Nesse sentido, as figuras geométricas podem ser analisadas, na perspectiva de Raymond Duval, como uma forma não discursiva de registros de representação semiótica, sendo encontrados vários trabalhos na literatura nacional ${ }^{1}$ que avaliam a importância das representações na aprendizagem da geometria (ALMOULOUD, 2011; FLORES \& MORETTI, 2006; KALEFF, 2007; MORETTI, 2011). Na literatura internacional, várias pesquisas sobre formação de imagens mentais utilizaram a teoria dos registros de representação semiótica para analisar as produções dos alunos advindas de

\footnotetext{
${ }^{1}$ Colombo et al. (2008) fizeram um levantamento das pesquisas realizadas no Brasil no período de 1990 a 2005 e que utilizam os pressupostos teóricos da teoria das representações semióticas; os resultados indicam que o trabalho com registros de representação semiótica possibilita uma melhor compreensão não apenas do objeto matemático em estudo por parte dos estudantes, como também da especificidade da aprendizagem em matemática.
} 
atividades de geometria (ALAIN, 2012; ELIA \& EVANGELOU, 2013; KALOGIROU et al., 2013; PITTALIS \& CHRISTOU, 2010; TORREGROSA \& QUESADA, 2007).

A elaboração de figuras geométricas - sejam elas feitas à mão livre ou com auxílio de malhas quadriculadas ou pontilhadas ou ainda de instrumentos de desenho geométrico - permite os "tratamentos" dos registros de representação semiótica e revelam alguns processos cognitivos específicos da atividade geométrica, como apreensão perceptual e operatória das figuras (DUVAL, 2009).

A utilização de softwares de geometria dinâmica na sala de aula propicia a construção de desenhos com régua e compasso virtuais a partir de propriedades geométricas: esta pode ser uma alternativa para tornar mais atraentes aquelas atividades antes feitas no papel. A revisão da literatura mostra que são muitas as pesquisas que evidenciam a contribuição desses softwares no desenvolvimento de conceitos e de habilidades em geometria (MEIER \& GRAVINA, 2012; VIEIRA, 2011).

Um software que tem merecido destaque nas pesquisas nacionais e internacionais sobre ensino e aprendizagem da geometria é o GeoGebra ${ }^{2}$, conforme pode ser verificado nos trabalhos de Edwards e Jones (2006), Hohenwarter e Jones (2007), Lovis e Franco (2013), Moran e Franco (2014), Oliveira e Araújo (2012) e Pereira (2012), entre outros. Este software, de acordo com Stormowski et al. (2013), teria um potencial semântico caracterizado pela "capacidade de relacionar conceitos matemáticos (identificáveis no software) com signos e significados que emergem do uso da ferramenta ou da realização da tarefa" (p. 1), que merece ser mais bem entendido para que possa ser incorporado como recurso tecnológico nas aulas de matemática.

O caso da construção de figuras geométricas parece exigir processos cognitivos de diferenciação entre desenho e figura, conforme Duval (2009). Se a reprodução for feita na tela do computador, o domínio do menu do software (na forma discursiva e figural) está relacionado à capacidade de formação, tratamento e conversão dos registros de representação semiótica. Realçam-se, aqui, os processos chamados por Duval (2009) de reconfiguração e de desconstrução dimensional - caracterizados pela identificação das partes de uma figura - e que devem ser ativados no caso de reprodução na tela do computador.

\footnotetext{
${ }^{2}$ O GeoGebra é um software livre que aborda assuntos da Geometria, da Álgebra e do Cálculo. Ele possui duas janelas de trabalho: a janela de álgebra e a janela geométrica; nesta, ocorrem as construções geométricas.
} 
Toma-se, como exemplo do exposto, a produção de um triângulo equilátero de lado $4 \mathrm{~cm}$ no GeoGebra. Ao que parece, o mesmo pode ser representado de, pelo menos, duas maneiras, conforme mostra a Figura 1.

Figura 1: Duas sequências distintas para a construção do triângulo no GeoGebra

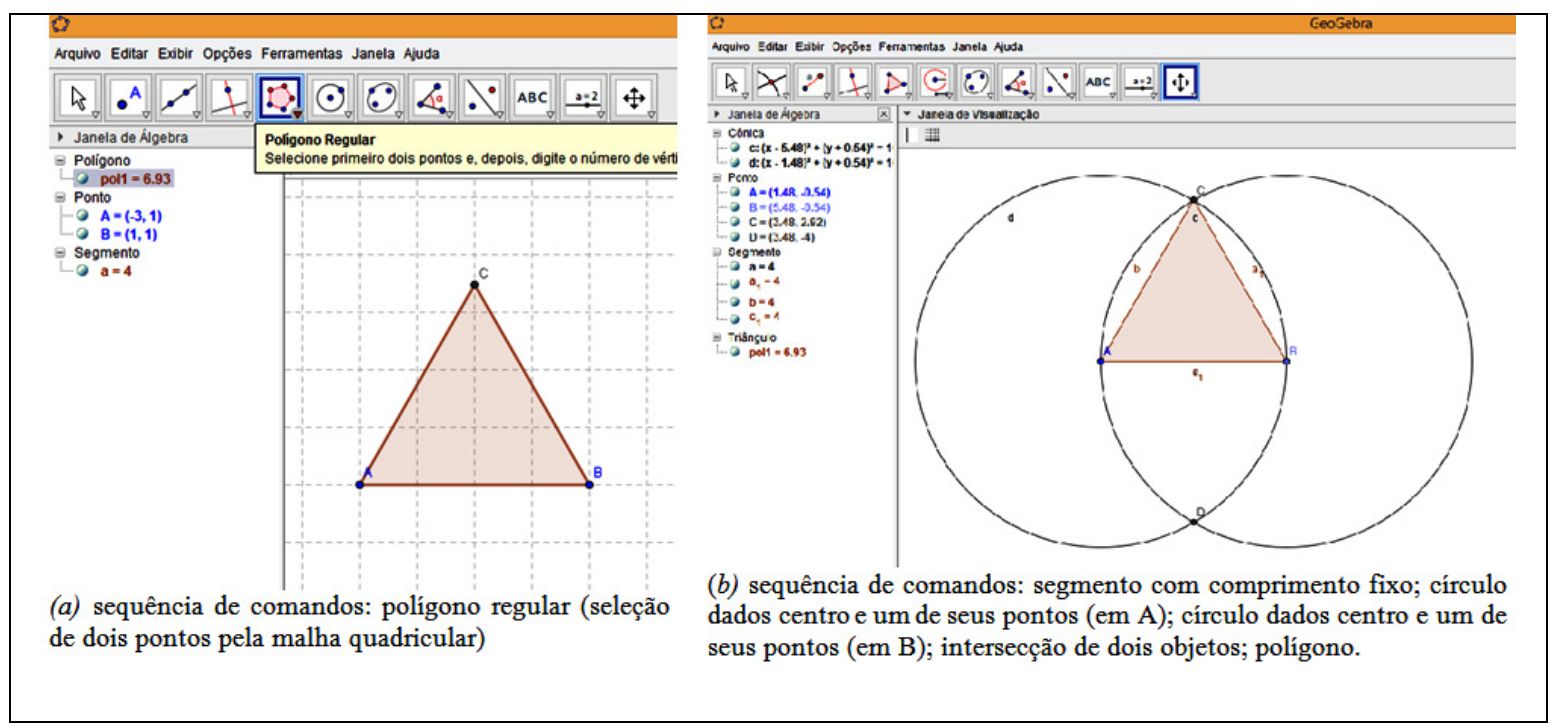

A escolha dos menus para as duas sequências apresentadas na Figura 1 parece envolver a identificação das unidades figurais de um nível inferior: o triângulo equilátero tem que ser identificado por suas unidades figurais, ou seja, três segmentos consecutivos e não colineares de mesma medida (polígono regular). No entanto, na sequência (a) a medida do lado é facilmente representada quando se usa a rede quadriculada e o desenho é construído pelo comando polígono regular; já na sequência (b) é necessária a intenção de estabelecer a medida para desenhar o primeiro lado, de buscar o terceiro vértice por meio da intersecção das duas circunferências de mesmo raio para, então, desenhar o polígono a partir dos três vértices. Cada sequência anunciada parece envolver conceitos e processos distintos de desconstrução.

Para Duval (2011a), apesar de os monitores de computadores não apresentarem um novo registro - já que as representações exibidas nas telas são as mesmas que aquelas produzidas graficamente no papel -, eles constituem outro modo fenomenológico de produção. Por exemplo, com softwares de geometria dinâmica as representações figurais podem ser manipuladas como se fossem objetos reais. O autor ainda observa que "um menu privilegia um registro de representação para obter a representação correspondente em outro registro" (p. 138). 
A experiência que deu origem à pesquisa aqui relatada foi realizada com alunos do ensino médio, que deveriam construir, na tela do GeoGebra, o desenho das figuras geométricas que tinham sido identificadas em um logotipo figural ${ }^{3}$. A revisão bibliográfica que pôde ser feita não encontrou trabalhos que analisassem as construções de figuras desse tipo no GeoGebra e que tivessem como base teórica as operações de reconfiguração e de desconstrução dimensional propostas por Duval.

Assim, tendo em vista que as atividades de desenho geométrico demandam conceitos e relações importantes na formação do raciocínio em geometria e que a conceitualização implica na coordenação de registros de representação semiótica; que as construções tendem a ser mais atrativas se forem feitas na tela do GeoGebra e que há processos cognitivos específicos envolvidos nesta construção, considerou-se importante refletir sobre a contribuição do software na aprendizagem da disciplina. Compreender como os estudantes do ensino médio - que já teriam formado os conceitos mais elementares de geometria plana descontroem as figuras, isto é, se valem desses conceitos para reconhecer as unidades figurais dos logotipos para construí-las na tela do GeoGebra, em atividades de geometria, foi o problema que originou esta pesquisa.

\section{Geometria e registros de representação semiótica}

Apesar da definição, aparentemente simples, da geometria escolar como sendo o estudo das formas, de suas propriedades e das relações entre elas, há várias dimensões ou paradigmas para interpretar o ensino da disciplina sob a ótica curricular, conforme ponderaram Houdement e Kuzniak (2003), Parsysz (2003) e Usiskin (1994).

É possível, por exemplo, conceber a disciplina como um exemplo de um sistema matemático - geometria axiomática formal - em que se trabalha com objetos ideais sem qualquer referência à realidade. Outra possibilidade é ver a geometria como estudo da visualização, do desenho e da construção de figuras ou ainda como maneira de explorar aplicações do mundo físico, privilegiando as medidas e a resolução de problemas.

Para o ensino básico, os PCN (BRASIL, 1998) insistem na importância do desenvolvimento do chamado pensamento geométrico que permitiria ao aluno "compreender, descrever e representar, de forma organizada, o mundo em que vive" (p. 51). Sugere-se a realização de algumas construções geométricas com régua e compasso como maneira de desenvolver a visualização e a aplicação de propriedades das figuras e indicam, para o ensino médio

\footnotetext{
${ }^{3}$ Logotipo figural é uma representação gráfica de uma marca comercial ou da sigla de uma instituição.
} REVEMAT. Florianópolis (SC), v.10, n. 1, p. 162-182, 2015. 
(BRASIL, 2006), o desenvolvimento de habilidades de visualização, de desenho, de argumentação lógica e de aplicação na busca de solução para problemas.

Optou-se por destacar o desenho geométrico, em especial aquele em que se utilizam régua e compasso, que caracteriza a geometria como estudo da visualização, do desenho e da construção de figuras. De acordo com Usiskin (1994), um ensino com essa perspectiva trataria de desenvolver os conceitos baseando-se principalmente nas habilidades visual e gráfica. Reconhecer figuras giradas e justapostas, compor e decompor figuras, reconhecer padrões em uma sequência de desenhos etc. seriam exemplos de atividades a desenvolver a habilidade visual dos alunos; as tarefas de desenhar figuras em redes pontilhadas ou quadriculadas, utilizar instrumentos de desenho (régua, transferidor, compasso etc.) e também se valer de softwares específicos desenvolveriam a habilidade gráfica dos estudantes.

Essa maneira de conceber o ensino da geometria pode ser confrontada com algumas ideias de Fischbein (1978) sobre os conceitos matemáticos que seriam, em uma primeira reflexão, construtos puramente mentais, isto é, os objetos aos quais a matemática se refere não teriam propriedades materiais. Uma distinção seria dada ao desenho de uma figura geométrica particular, já que esta pode representar tanto a forma de uma classe infinita de objetos, assim como refletir propriedades espaciais como tamanho e posição. Fischbein (1978) afirma, então, que as figuras geométricas são entidades que possuem uma natureza dual, com componentes figurais e conceptuais, denominadas de "conceitos figurativos".

A natureza dual das figuras geométricas pode ser entendida quando se toma por base a teoria de Raymond Duval, que traz uma extensa análise sobre a importância dos desenhos, figuras e imagens na aprendizagem de conceitos geométricos. Nessa linha, os desenhos de figuras geométricas podem ser concebidos como registros de representação semiótica, conforme definidos por Duval (2005, 2009, 2011a, 2011b, 2012).

A noção de representação é fundamental para o estudo dos fenômenos relativos ao conhecimento e, de acordo com Duval (2009), "não há conhecimento que não possa ser mobilizado por um sujeito sem uma atividade de representação" (p. 29). No entanto, há distinção entre um objeto e sua representação - que pode se dar na forma de símbolos, de traçados, de figuras - e este é um ponto estratégico para a compreensão em matemática.

Buscando elementos que caracterizam o pensamento matemático, Duval (2012) diferencia apesar de não colocá-las em domínios distintos - as representações mentais das representações semióticas: 
As representações mentais pautam-se num conjunto de imagens, e mais globalmente, as conceitualizações que um indivíduo pode ter sobre um objeto, sobre uma situação e sobre o que lhe é associado. As representações semióticas são produções constituídas pelo emprego de signos pertencentes a um sistema de representação que possui inconvenientes próprios de significação e de funcionamento. (p.269).

O autor pondera que as representações semióticas são, muitas vezes, consideradas como um simples meio de exteriorização de representações mentais para fins de comunicação com o intuito de tornar uma informação visível ou acessível para outrem. Para romper com esta ideia, justifica que as representações semióticas não estão subordinadas às representações mentais e são, ainda, essenciais à atividade cognitiva do pensamento: elas desempenham um papel primordial no desenvolvimento das representações mentais (muitas representações mentais são representações semióticas interiorizadas), na realização de diferentes funções cognitivas e na produção de conhecimentos.

Duval (2009) vale-se de dois conceitos para esclarecer as relações existentes entre os registros de representação semiótica e as representações mentais: a semiósis - apreensão ou a produção de uma representação semiótica - e a noésis - apreensão conceitual de um objeto matemático. O mesmo pontua que não há noésis sem semiósis, sendo necessária uma pluralidade de sistemas e a coordenação destes para uma pessoa apreender conceitualmente um objeto matemático.

Para que um sistema semiótico seja um registro de representação, ele necessita atender às características das três atividades cognitivas fundamentais ligadas à semiose: formação, conversão e tratamento de uma representação.

A formação diz respeito ao modo de produção da representação de um registro dado (enunciação de uma frase, composição de um texto, desenho de uma forma geométrica, elaboração de um esquema, expressão de uma fórmula, dentre outras) e deve respeitar regras de modo a assegurar as condições de identificação e de reconhecimento da representação e também a possibilidade de tratamentos. Duval (2011a) afirma que "a produção de uma representação semiótica precede de alguma maneira o pensamento dos objetos que se encontram assim representados" (p.99), o que explica a função de objetivação, ou de tomada de consciência na atividade cognitiva de formação.

O tratamento de uma representação é a transformação desta representação internamente, utilizando regras de funcionamento dentro de um mesmo registro semiótico em que esta foi formada. Há regras de tratamento próprio a cada registro: por exemplo, na geometria, um tipo particular de tratamento com figuras é o de reconfiguração. 
Finalmente, a conversão de uma representação é a transformação desta função em outro registro, conservando a totalidade ou uma parte apenas do conteúdo da representação inicial; esta seria uma transformação externa a um registro dado, por exemplo, a figura, a tradução de um texto de uma língua para outra, a descrição etc. A conversão é uma atividade cognitiva diferente e independente do tratamento, já que exige que as unidades significantes propostas para cada registro sejam bem discriminadas. Apesar de a mobilização de um segundo registro ser necessária para poder discernir e reconhecer as unidades de sentido do primeiro registro, esta não é suficiente, já que é necessária uma coordenação dos registros para garantir a conversão das representações, "o primeiro limiar da compreensão em matemática" (DUVAL, 2011a, p.100).

Assim, no processo de ensino e aprendizagem da matemática escolar, apesar de a apreensão dos objetos ser conceitual, a atividade cognitiva sobre esses objetos só é possível por meio das representações semióticas. Duval (2012) afirma que "as transformações de representações em outras transformações semióticas estão no coração da atividade; as dificuldades dos alunos para compreender matemática surgem por conta da diversidade e complexidade dessas transformações" (p. 266).

O entendimento dessas regras de transformação com figuras geométricas na perspectiva dos registros de representação semiótica talvez explique parte das dificuldades dos alunos nas tarefas de geometria.

\section{O desenho geométrico}

Duval (2009, p. 91) distingue desenho de figura. O desenho seria "a configuração particular que é mostrada no papel, no quadro - negro ou no monitor do computador" enquanto "a figura seria as propriedades do objeto representado pelo desenho ou, ainda, a classe de todos os desenhos que podem ser representações visuais desse objeto".

Para o autor, essa diferenciação explicaria parte das dificuldades dos alunos em geometria, já que "a figura é identificada pelas propriedades que não vemos porque nenhum desenho as mostra em sua generalidade; essas propriedades só podem ser aprendidas por conceitos" (Duval, 2009, p. 91). Para um mesmo desenho, é possível que o professor e o aluno tenham hipóteses conceituais diferentes, uma vez que a interpretação das figuras envolve diferentes tipos de apreensão, em que se destacam as apreensões perceptiva, operatória, discursiva e sequencial das figuras (Duval, 2012). 
Duas classes de operações são definidas na chamada apreensão operatória de uma figura (ou tratamento figural): as operações mereológicas de reconfiguração e as de desconstrução dimensional.

As operações mereológicas de reconfiguração apoiam-se na percepção; elas permitem modificações ou decomposições da figura em unidades figurais de mesma dimensão. A decomposição pode se dar por justaposição ou por superposição - estas duas maneiras são visualmente incompatíveis.

Já as operações de desconstrução dimensional das formas $(n D \rightarrow(n-1) D)$ permitiriam "ver" matematicamente, ou seja, operar sobre "as formas que reconhecemos imediatamente em outras formas que não enxergamos à primeira vista, e isso sem que nada mude na figura afixada no monitor ou construída no papel" (Duval, 2011a, p.87). No caso de uma figura tridimensional (3D), a desconstrução refere-se a identificar, por exemplo, as faces bidimensionais $(2 D)$ de um poliedro. No caso de uma figura plana $(2 D)$, a identificar, por exemplo, os lados de um polígono (1D).

De acordo com o autor, "a desconstrução dimensional é onipresente em toda definição, em todo raciocínio e em toda explicação em relação às figuras em geometria” (DUVAL, 2009, p. 90).

Concluindo a importância da "apreensão operatória" em geometria, afirma que:

[...] toda utilização heurística das figuras na resolução de problemas, toda explicação de uma propriedade com a ajuda de figuras (ou manipulação de material), toda articulação do enunciado de propriedades com uma figura para justificar ou demonstrar uma conjectura dependem inteira e exclusivamente dessas duas operações figurais. (Duval, 2009, p. 90).

As atividades escolares ao desenho geométrico com régua e compasso parecem depender, em maior grau, das operações de desconstrução dimensional. Estas podem ser identificadas quando o sujeito desenha, por exemplo, um retângulo de medidas $2 \mathrm{~cm}$ e $3 \mathrm{~cm}$. Feita no papel ou na tela do computador por meio de um software, a construção geométrica solicitada pressupõe operações de desconstrução dimensional do retângulo $(2 D)$ em retas e segmentos paralelos e/ou perpendiculares $(1 D)$ - o que implica na identificação da figura pelas propriedades que só podem ser aprendidas por conceitos.

No caso do menu do GeoGebra, verifica-se que as etapas para a construção do desenho geométrico podem ser simplificadas e que a escolha do comando depende também da forma figurativa e discursiva como esses conceitos são apresentados. A Figura 2 mostra três sequências distintas para a construção de um retângulo. 
Figura 2: Três sequências distintas para a construção do retângulo no GeoGebra

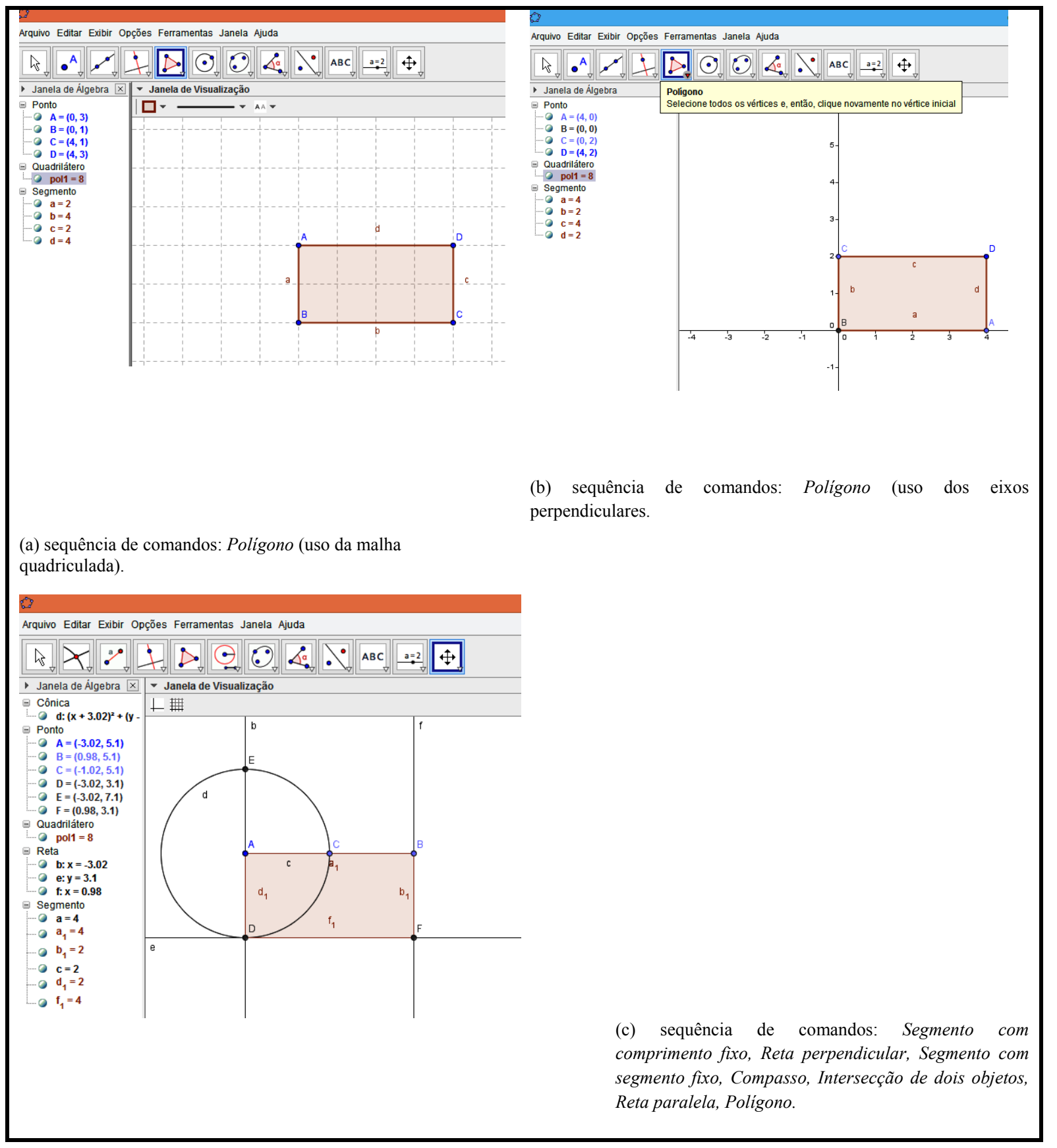

As três sequências apresentadas na Figura 2 demonstram não apenas a identificação das unidades figurais (de uma dimensão) do retângulo, mas também uma ordenação das ações a serem realizadas e isto pode ser verificado pela escolha dos comandos do menu do software. Nas sequências (a) e (b) as medidas e também o perpendicularismo/paralelismo dos lados são facilmente representados pela rede quadriculada ou por um sistema de coordenadas cartesianas ortogonais. Nestes casos, as propriedades do quadrilátero ABCD desenhado não são mantidas se for movimentado qualquer dos vértices por meio do comando mover, a menos 
que se tenha utilizado o comado polígono rígido. Já na sequência (c) são necessários o estabelecimento das medidas, a identificação de segmentos consecutivos, a transposição de medidas por meio do compasso, o traçado de retas paralelas ou perpendiculares, a intersecção das curvas etc. É possível mover o retângulo em movimentos de rotação e translação, mantendo-se as propriedades da figura.

Para Duval (2011a), esse aspecto dinâmico de tratamento dos registros - que é proporcionado pelo computador - desempenha a função de simulação: as representações não discursivas tornam-se manipuláveis como objetos reais.

De qualquer forma, para construir uma figura utilizando um software de geometria, o menu verbal impõe que se antecipe a desconstrução em unidades figurais $0 \mathrm{D}$ e 1D, conforme afirma Duval (2011a). Assim, considerou-se que as sequências de comandos do GeoGebra utilizadas em tarefas de construção de figuras geométricas poderiam revelar processos de apreensão operatória de uma figura, especificamente de desconstrução dimensional.

\section{Método}

A pesquisa teve por objetivo analisar algumas construções geométricas elaboradas no GeoGebra em atividades de geometria. Especificamente, pretendeu-se verificar, por meio das sequências elaboradas pelos alunos, alguns processos cognitivos ligados às operações mereológicas de reconfiguração e de desconstrução dimensional, na perspectiva da teoria dos registros de representação semiótica.

A análise teve por base a teoria de Duval, para quem as representações produzidas na tela de um computador são representações semióticas (DUVAL, 2011a, p.137).

Considera-se também que "a teoria dos registros é sua própria metodologia [já que] resulta primeiro da descrição da atividade matemática como transformação de representações semióticas" (Duval, 2011a, p. 151). O autor defende que se devam considerar as produções de alunos em uma perspectiva de pesquisa, sejam elas colhidas no trabalho em sala de aula como é o caso aqui relatado - sejam em questionários propostos para populações maiores.

No entanto, o autor adverte para não confundir os dois tipos de análise: a análise matemática e a cognitiva. A primeira permite analisar as produções em função de conhecimentos específicos da área, mas verificar acertos e erros não permitiria entender as dificuldades dos alunos; já a análise cognitiva, que consiste em decompor as soluções apresentadas em tratamentos e conversões segundo os registros mobilizados, contribui para compreender como o aluno articula conhecimentos em situações distintas. No caso dos registros produzidos no 
computador, Duval (2011a) considera que se pode analisar as tarefas cognitivas requeridas pela utilização do software em função das ações permitida pelo seu menu.

Participaram da pesquisa ${ }^{4}$ trinta alunos do terceiro ano do ensino médio de uma instituição federal de ensino, sendo o grupo considerado uma amostra de conveniência.

As construções geométricas fizeram parte de uma série de atividades propostas para o ensino da geometria, por meio da modelagem matemática ${ }^{5}$ de logotipos figurais. Os estudantes tinham que escolher um logotipo figural que contivesse formas geométricas de modo a reproduzi-las no GeoGebra; as construções produzidas foram entendidas como sendo um modelo geométrico do logotipo figural, ou seja, uma composição de figuras que representavam, ainda que de forma incompleta, aspectos geométricos do desenho escolhido. Os participantes tinham também que indicar a sequência de comandos utilizada na construção no GeoGebra, redigindo um pequeno texto e/ou tirando print screen da tela, a cada ação realizada.

Acrescenta-se que, antes de iniciar o processo de modelagem do próprio logotipo, os alunos tiveram orientação de como realizar o trabalho, já que o professor mostrou-lhes uma sequência elaborada para um logotipo figural, como exemplo dos procedimentos que estavam sendo requeridos para a atividade.

As operações cognitivas envolvidas nas sequências elaboradas pelos alunos foram analisadas em duas etapas: (a) na de reconfiguração, em que as unidades figurais foram reconhecidas e estabelecidas as relações entre propriedades e (b) na de desconstrução dimensional, em que foram evidenciados os comandos utilizados para construção das figuras que compunham o logotipo figural.

Optou-se por apresentar, neste trabalho, sete sequências, escolhidas por ilustrarem as operações analisadas de forma mais adequada.

\section{Resultados e discussão}

A partir da escolha do logotipo figural a ser modelado, a primeira atividade proposta foi a identificação das figuras geométricas que o compunham. Conforme aponta Duval (2011a, p.86), "existem sempre várias maneiras de reconhecer as formas, mesmo que o fato de

\footnotetext{
${ }^{4}$ A pesquisa aqui relatada é uma parte da dissertação de mestrado profissional do segundo autor deste trabalho e caracterizou-se como pesquisa do professor, em que este é o próprio pesquisador de sua prática (CARNEIRO, 2012).

${ }^{5}$ Neste trabalho, a modelagem matemática foi entendida como o processo de obtenção de um modelo, ou seja, um conjunto de conceitos e de símbolos matemáticos que busca retratar, ainda que parcialmente, aspectos da realidade a ser modelada (BIENGENGHUT \& HEIN, 2007).
} 
reconhecer umas exclui a possibilidade de reconhecer outras". As operações cognitivas que permitem esse reconhecimento, ou seja, as operações mereológicas de reconfiguração permitiram aos estudantes a separação da figura em unidades figurais de mesma dimensão (subfiguras da figura dada). O reconhecimento foi mostrado pela demarcação dos contornos coloridos das figuras, por justaposição, mas também o estudante valeu-se de frases, o que caracterizou algumas operações de designação verbal, na perspectiva de Duval (2011a) para representações discursivas. A Figura 3 mostra como dois estudantes representaram esta primeira etapa.

Figura 3: Representações relativas às operações mereológicas de reconfiguração dos logotipos figurais (A), (B) e (C)

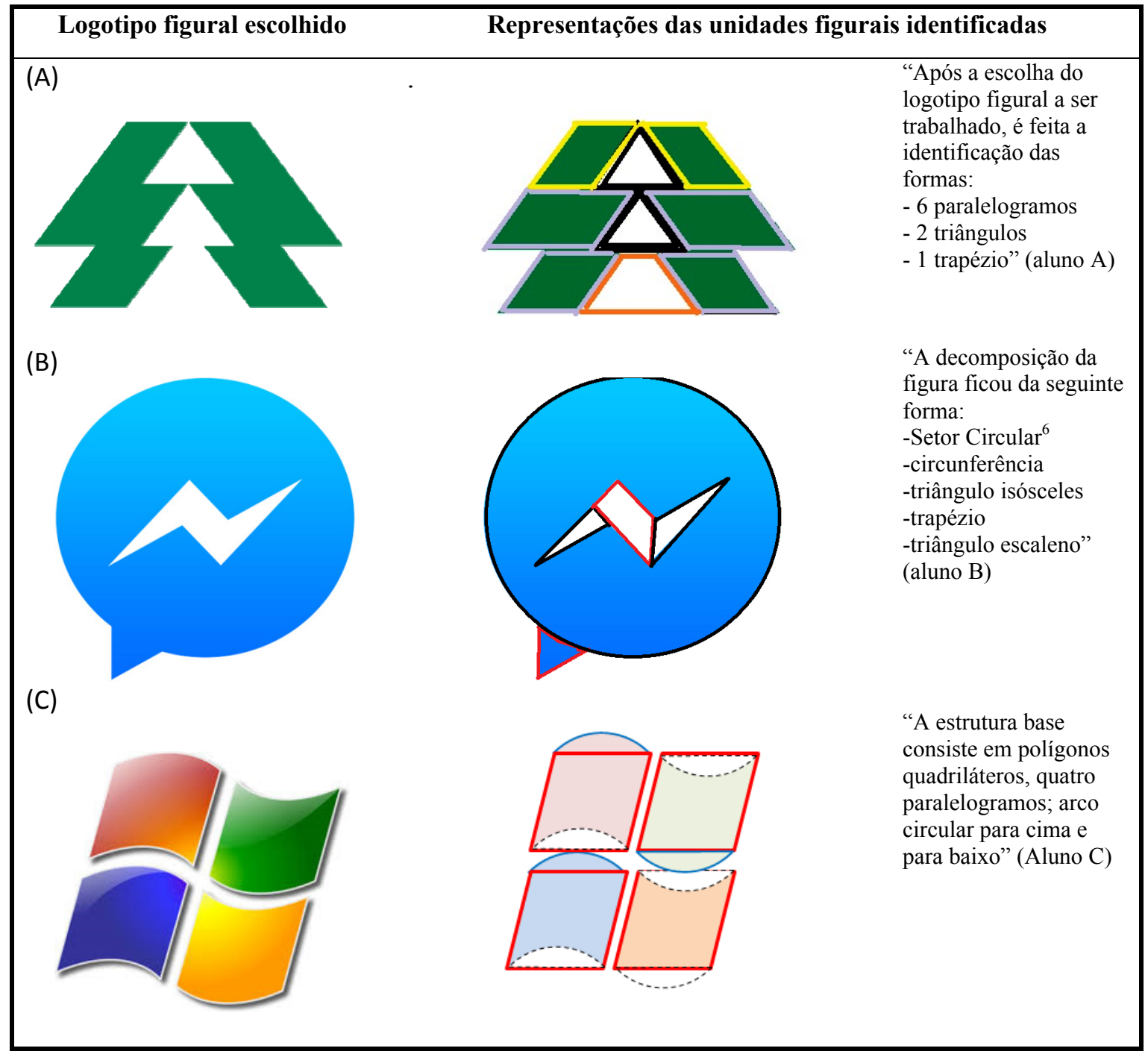

A segunda atividade consistia na construção das figuras no GeoGebra acompanhada da descrição dos comandos utilizados. Essa etapa requereu dos alunos o emprego das operações

${ }^{6}$ Note-se que a figura identificada em (B) vermelho não é um setor circular. 
mereológicas de desconstrução; por exemplo, um polígono identificado na etapa anterior é descontruído em segmentos (2D) e estes, em pontos (0D). A Figura 4 mostra uma sequência de desconstrução dimensional da figura, sendo mostradas também as designações verbais do estudante.

Figura 4: Representações relativas às operações mereológicas de desconstrução dimensional do logotipo figural (D)

(D)

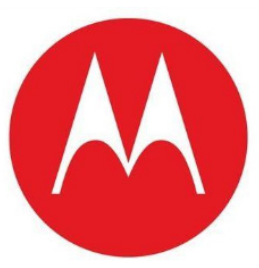

ii)

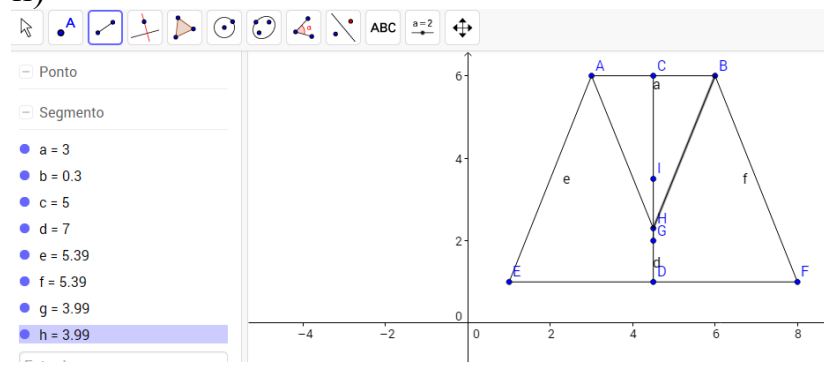

iii)

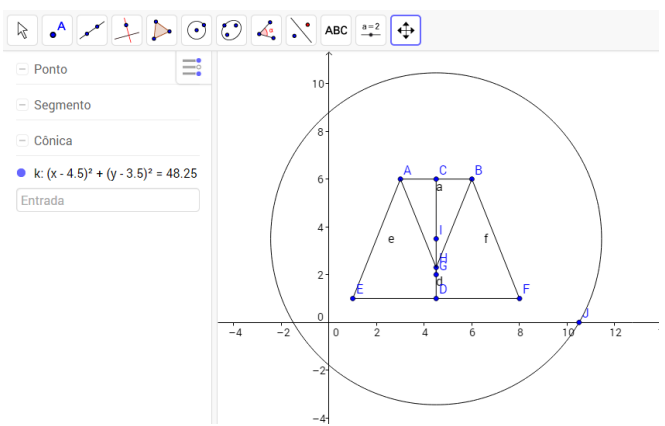

i)

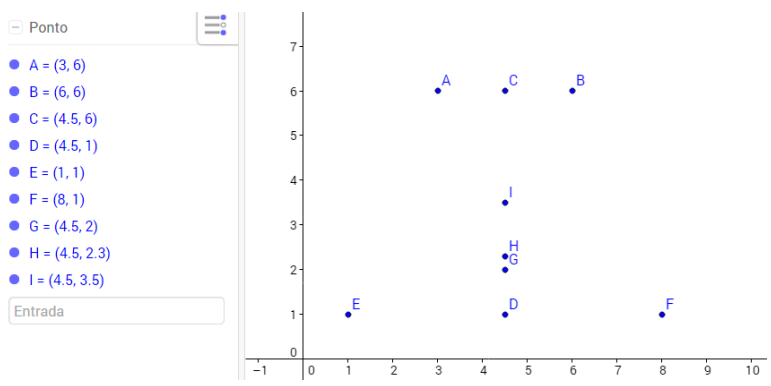

"Depois de determinados os pontos, de acordo com as supostas figuras, exemplo: os pontos (A,B,E,F) formam um trapézio; os pontos $(\mathrm{A}, \mathrm{I}, \mathrm{B})$ formam um triângulo; os pontos $(\mathrm{C}, \mathrm{D})$ formam um segmento, que intercepta os pontos $(\mathrm{I}, \mathrm{H}, \mathrm{G})$, que posteriormente formaram ligações"'(Aluno C)

iv) "Duas elipses, assim foram definidos os pontos, sendo que os pontos ( $\mathrm{R}$ e $\mathrm{Q})$ são dispensáveis. Assim criamos os focos das elipses, definidos por (K,L,M,N) após ser selecionada a opção das cônicas, a opção da elipse, é necessário arrastar até que corte o ponto (G)" (Aluno C)

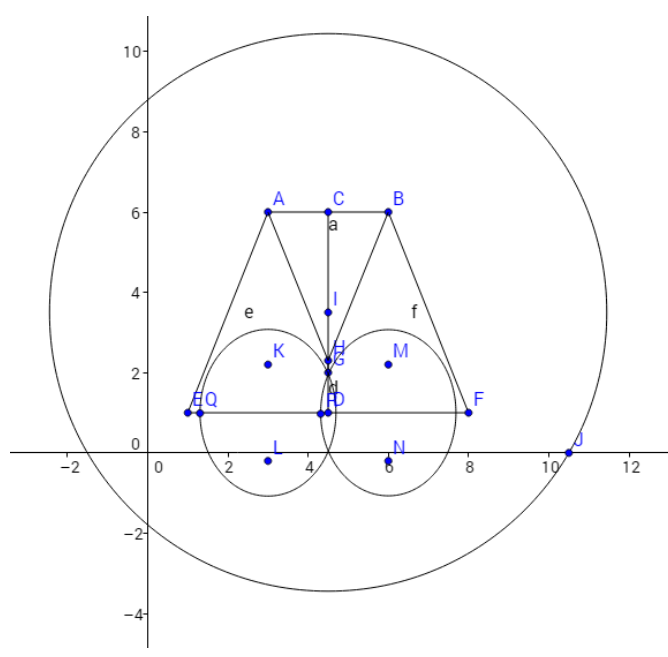

A ideia de antecipação proposta por Duval (2011a) pode ser verificada na sequência apresentada na Figura 4: esta mostra que o aluno em (i) e em (iv) antecipa a desconstrução localizando os pontos que irão definir as figuras que compõem o logotipo. Uma leitura mais 
atenta da sequência permite verificar que os pontos foram localizados a partir dos eixos perpendiculares, o que garantiu algumas medidas dos segmentos, além da simetria que fora percebida na figura. Aliás, a simetria foi a base para a determinação quase que aleatória dos pontos que serviram para os vértices dos polígonos, o centro da circunferência e os focos das elipses.

A utilização dos eixos perpendiculares e da malha quadriculada que aparecem na tela do GeoGebra foram base para as sequências $(E)$ e $(F)$ mostradas na Figura 5.

Figura 5: Representações relativas às operações mereológicas de desconstrução dimensional dos logotipos figurais (E), (F) e (G)

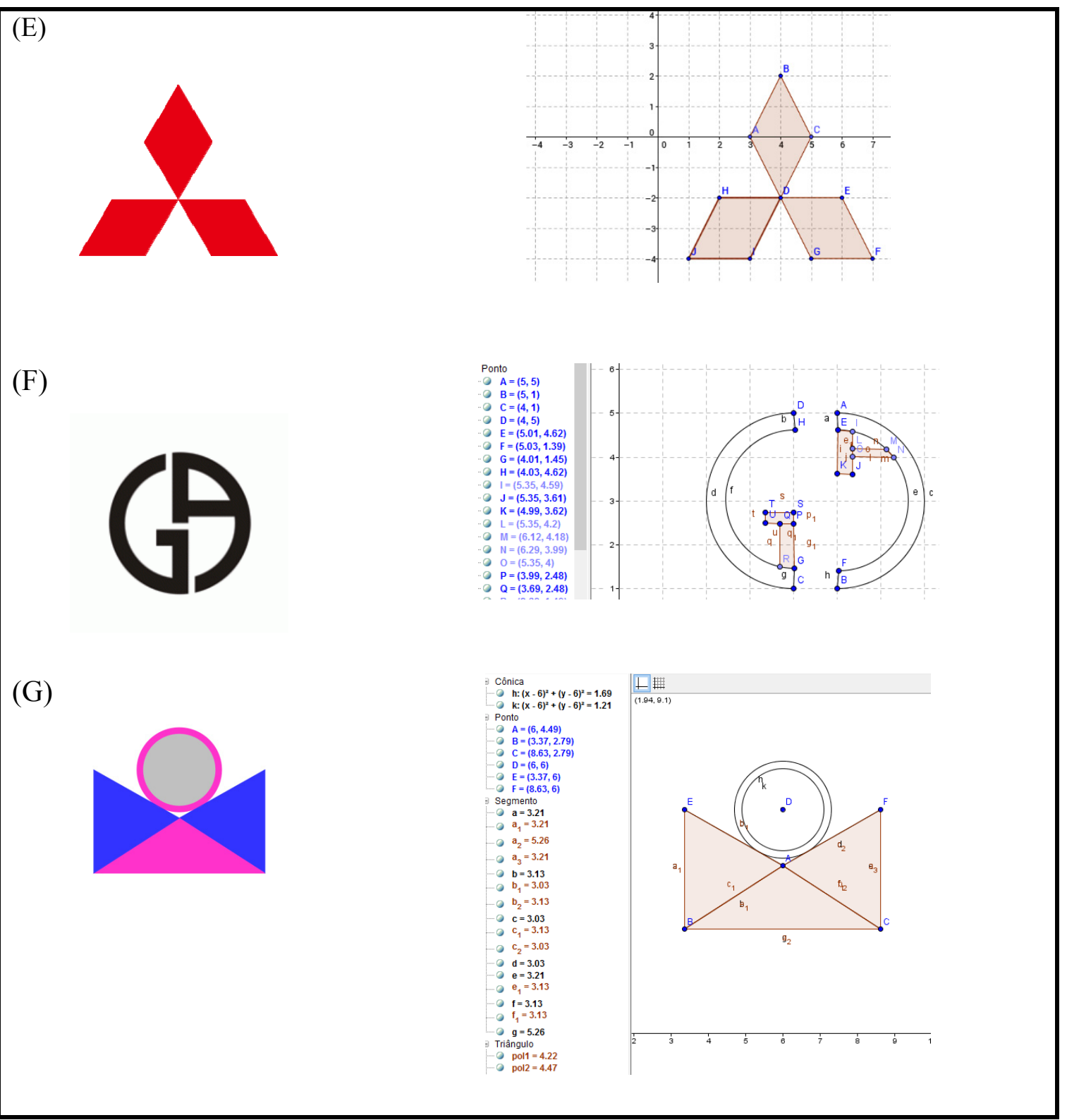


Analisando a sequência produzida para o logotipo (E), cuja representação final é mostrada na Figura 5, foi possível identificar os comandos polígono regular de três lados que, uma vez repetido acima e abaixo do eixo horizontal, formou o losango. No entanto, os dois outros quadriláteros formados não têm lados congruentes: a ausência do reconhecimento desta propriedade comprometeu a qualidade da representação final. Já a sequência de pontos mostrados na janela de álgebra da representação do logotipo (F) mostra que a malha quadricular não foi suficiente para garantir o paralelismo e perpendicularismo das unidades figurais reconhecidas (por exemplo, os pontos $\mathrm{F}$ e B não têm a mesma abscissa e $\mathrm{J}$ e $\mathrm{K}$ não têm a mesma ordenada). Concorda-se com Duval (2011a) quando afirma que a decomposição imposta pelos menus pode não ser congruente com a forma como se decompõe uma figura.

Nota-se, no logotipo (G), que o aluno não utilizou a malha quadriculada e que a escolha dos comandos parece ter sido orientada pela simetria da figura; o mesmo não se valeu de lugares geométricos (por exemplo, a mediatriz), nem de pontos de intersecção entre figuras e também não identificou o ponto de tangência para a construção da circunferência de raio maior.

Acrescenta-se que o comando compasso - que demandaria a ideia de lugar geométrico, ferramenta fundamental das atividades de desenho geométrico (GAITA \& ORTEGA, 2014; OLIVEIRA \& ARAUJO, 2012) - não foi utilizado por nenhum dos alunos participantes da pesquisa relatada, o que indica diferenças na atividade de desenho geométrico no papel e no software.

\section{Algumas conclusões e considerações finais}

Apesar das indicações dos documentos oficiais (BRASIL, 1998; 2006) acerca do desenvolvimento de habilidades de visualização e de desenho e da possibilidade de que a exploração de situações envolvendo construções geométricas com régua e compasso contribua para a aprendizagem da geometria básica - assim como apontado por Jucá (2011), Kopke (2006) e Zuin (2001) - é possível fazer um alerta a respeito do uso do software GeoGebra neste contexto. Concorda-se com Stormowski et al. (2013) que é necessário compreender o potencial semântico do software e os significados que emergem do seu uso para que possa ser incorporado como recurso tecnológico nas aulas de matemática.

A atividade de construção geométrica das figuras identificadas em um logotipo, quando feita na tela do GeoGebra, parece exigir dos alunos operações cognitivas que ultrapassam aquelas 
requeridas no desenho geométrico convencional, isto é, em que se solicita a construção de alguma figura ou de seus elementos a partir de informações sobre as unidades figurais.

Conforme aponta Duval (2011a), um menu privilegia um registro de representação para obter a representação correspondente em outro registro; para a aprendizagem, é necessário desenvolver a coordenação dos registros, efetuando a entrada inversa. O menu do GeoGebra parece facilitar essa coordenação, uma vez que cada comando é ilustrado com a denominação verbal e também com a representação figurativa, seguida da indicação do procedimento da construção. Além disso, ao clicar sobre o desenho pronto, há a possibilidade de se identificarem os nomes das figuras e de algumas relações.

$\mathrm{Na}$ primeira fase da atividade puderam ser analisadas as operações mereológicas de reconfiguração: foi possível verificar que, na identificação das unidades figurais, os alunos trataram os registros de duas maneiras: por demarcação dos contornos das figuras (representações figurais) ou por designação verbal (representações discursivas). Para Duval (2011b, p, 28), "tarefas de estrito reconhecimento são tão importantes para a aprendizagem da matemática quanto as tarefas de produção", já que o nível de compreensão que um aluno pode alcançar depende do seu grau de iniciativa e de sua capacidade de exploração. Além disso, nota-se que a atividade requereu as transformações necessárias para o desenvolvimento do pensamento matemático: o tratamento e a conversão de registros de representações semióticas.

A fase seguinte, de desconstrução dimensional - "onipresente em toda definição, em todo raciocínio e em toda explicação em relação às figuras em geometria" (DUVAL, 2009, p. 90) necessitava da escolha de comandos no menu do software e pareceu revelar novas transformações dos registros ali encontrados. Assim, mesmo tendo identificado, na forma figural ou discursiva, algumas unidades figurais, a sequência de comandos não indicava que o aluno convertia os registros de representação de forma adequada: muitas propriedades das figuras não foram atendidas, como é o caso do paralelismo dos lados do retângulo e do ponto de tangência entre reta e circunferência - menus não escolhidos por eles.

Espera-se que este trabalho contribua para o entendimento de alguns processos cognitivos específicos da atividade geométrica, base para as possibilidades de tratamento e conversão das representações, já que o software permite interpretar e construir figuras envolvendo os 
diferentes tipos de apreensão em geometria, conforme apontam Moran e Franco (2014), entre outros autores da literatura específica.

Outros estudos estão sendo realizados com o objetivo de aprofundar o entendimento sobre o modo fenomenológico de produção a partir do GeoGebra em atividades voltadas para a formação de conceitos, princípios e relações que caracterizam o chamado raciocínio geométrico dos estudantes.

\section{Referências}

ALAIN, K. Understanding the nature of the geometric work through its development and its transformations. International Congress on Mathematical Education, 12. Seoul, Korea, 2012. Anais... Seoul, Korea, 2012, p.. Disponível em:< www.icme12.org/upload/submission/1922 f.pdf > Acesso em: 08 fev. 2015.

ALMOULOUD, S.A. Registros de representação semiótica e compreensão de conceitos geométricos. In: Machado, S. D. A. (org.). Aprendizagem em matemática: registros de representação semiótica. Campinas, SP: Papirus, 2011, p. 125 - 148.

BRASIL. Ministério da Educação. Secretaria de Educação Fundamental. Parâmetros Curriculares Nacionais: Matemática. ( $3^{\circ}$ e $4^{\circ}$ ciclos do ensino fundamental). Brasília: MEC, 1998.

BRASIL. Ministério da Educação. Ciências da natureza, matemática e suas tecnologias Orientações curriculares para o ensino médio; volume 2. Secretaria de Educação Básica, 2006.

BIEMBENGUT, M. S.; HEIN, N. Modelagem Matemática no Ensino. 4. São Paulo: Contexto, 2007.

CARNEIRO, V.C. Contribuições para a Formação do Professor de Matemática Pesquisador nos Mestrados Profissionalizantes na Área de Ensino. Bolema, Rio Claro (SP), Ano 21, n 29 , 2008, p. 199 a 22.

COLOMBO, J. A. M.; FlORES, C.R.; MORETTI, M. T. Registros de representação semiótica nas pesquisas brasileiras em Educação Matemática: pontuando tendências. Zetetiké, Cempem, FE - Unicamp, v. 16, n. 29, 2008, p.41-72.

DUVAL, R. Les conditions cognitives de l'apprentissage de la Géométrie : développement de la visualisation, différenciation des raisonnements et coordination de leurs fonctionnements. Annales de Didactique et Sciences Cognitives, v. 10, p. 5 - 53, 2005. Disponível em: < http://turing.scedu.umontreal.ca/annales/documents/volume\%2010/Duval.pdf >. Acesso em: 08 fev. 2015. 
DUVAL, R. Semiósis e Pensamento Humano: registros semióticos e aprendizagens intelectuais. (Levy, L. F.; Silveira, M. R. A., Trad.). São Paulo: Livraria da Física, 2009.

DUVAL, R. Ver e ensinar a matemática de outra forma: entrar no modo matemático de pensar: os registros de representações semióticas. (Campos, T. M. M., Org.; Dias, M. A. D. Org.). São Paulo: PROEM, $2011 a$.

DUVAL, R. Registros de representações semióticas e funcionamento cognitivo da compreensão em matemática. In: MACHADO, S. D. A. (org). Aprendizagem em matemática: registros de representação semiótica. Campinas: Papirus, 11-33, $2011 b$.

DUVAL, R. Registros de representação semiótica e funcionamento cognitivo do pensamento. (Moretti, M. T., Trad.). Revemat: R. Eletr. de Edu. Matem. Florianópolis, 07, 2, p. 266 - 297, 2012. Disponível em: < https://periodicos.ufsc.br/index.php/.../view/19811322.2012v7n2p266> Acesso em: 08 fev. 2015.

EDWARDS, J. ; JONES, K. Linking geometry and algebra with GeoGebra, Mathematics Teaching, 194, p. 28 - 30, 2006.

ELIA, I.; EVANGELOU, K. Kindergarten teachers' use of semiotic resources in providing early learning experiences in geometry with a picture book as a didactical tool. In: Lindmeier, A. M. \& Heinze, A. (Eds.). Proceedings of the 37th Conference of the International Group for the Psychology of Mathematics Education, 2, 257 - 264. Kiel, Germany: PME, 2013.

FISCHBEIN, E. Schèmes virtuels et schèmes actifs dans l'apprentissage des sciences. Revue française de pédagogie. V. 45, 1978. p. 119-125. Disponível em: < http://www.persee.fr/web/revues/home/prescript/article/rfp 0556$7807 \quad 1978$ num $45 \quad 1$ 1677>. Acesso em: 08 fev. 2015.

FLORES, C.R.; MORETTI, M. T. As figuras geométricas enquanto suporte para a aprendizagem em geometria: um estudo sobre a heurística e a reconfiguração. RevematRevista Eletrônica de Educação Matemática - UFSC. 1, 5 - 13, 2006. Disponível em: < https://periodicos.ufsc.br/index.php/revemat/article/download/.../12088> $>$. Acesso em: 09 fev. 2015.

GAITA, C.; ORTEGA, T. Concepciones sobre lugar geométrico en estudiantes de arquitectura Educ. Matem. Pesq., São Paulo, v.16, n.4, pp. 1133-1145, 2014.

HOHENWARTER, M.; JONES, K. BSRLM. Geometry Working Group: ways of linking geometry and algebra, the case of Geogebra. Proceedings of the British Society for Research into Learning Mathematics, 27, (3),126-131, 2007.

HOUDEMENT, C.; KUZNIAK, A. Elementary geometry split into different geometrical paradigms. CERME 3: Third Conference of the European Society for Research in Mathematics Education. Bellaria, Italy, 2003. Anais...2003. Disponível em < http://www.dm.unipi.it/ didattica/CERME3/proceedings/Groups/groups.html >Acesso em: 08 fev. 2015. 
JUCÁ, A. M. Construções geométricas no ambiente virtual de ensino telemeios com mediação na sequência Fedathi. Tese de Doutorado em Educação. Universidade Federal do Ceará, 2011.

KALEFF, A. M. R. (2007) Registros Semióticos e Obstáculos Cognitivos na Resolução de Problemas Introdutórios às Geometrias não-Euclidianas no Âmbito da Formação de Professores de Matemática. Bolema, Rio Claro, 20, 28, 69 - 94.

KOPKE, R. C. M. Geometria, Desenho, Escola e Transdisciplinaridade: abordagens possíveis para a Educação. Tese de Doutorado em Educação. Universidade Federal do Rio de Janeiro. Rio de Janeiro, 2006.

LAMONATO, M.; PASSOS, C. L. B. Aprendizagens de professoras da educação infantil: possibilidades a partir da exploração-investigação em geometria. Ciências \& Cognição. 14 (2), $92 \quad-\quad$ 112, 2009. Disponível em: < http://www.cienciasecognicao.org/revista/index.php/cec/article/view/73 > Acesso em: 14 dez. 2014.

LOVIS, K.; FRANCO, V. S. Reflexões sobre o uso do GeoGebra e o ensino de Geometria Euclidiana. Informática na Educação: teoria e prática, Porto Alegre, v. 16, n. 1, p. 149-160, jan./jun. 2013. Disponível em:

http://seer.ufrgs.br/InfEducTeoriaPratica/article/view/26104>. Acesso em: 12 fev. 2015.

MEIER, M.; GRAVINA, M. A. Modelagem no GeoGebra e o desenvolvimento do pensamento geométrico no Ensino Fundamental. Conferência Latino Americana de GeoGebra, 1. São Paulo, 2012, São Paulo, SP. Anais..., p. 250 - 264, 2012.

MORAN, M. FRANCO, V. S. Registros Figurais em Geometria: influências na apreensão operatória e na pesquisa heurística de figuras. Perspectivas da Educação Matemática UFMS - v. 7, n. 13, 2014, p. 124 - 137. Disponível em: < http://seer.ufms.br/index.php/pedmat/article/view/494>. Acesso em: 12 fev. 2015.

MORETTI, M. T. A translação como recurso no esboço de curvas por meio da interpretação global de propriedades figurais. In: Machado, S. D. A. (org.). Aprendizagem em matemática: registros de representação semiótica. Campinas, SP: Papirus. 149 - 160, 2011.

OLIVEIRA, G. P.; ARAUJO, P. B. Uma abordagem para o ensino de lugares geométricos com o GeoGebra. Revemat: R. Eletr. de Edu. Matem. Florianópolis, v. 07, n. 2, p. 209-222, 2012. Disponível em: < https://periodicos.ufsc.br/index.php/revemat/article/view/19811322.2012v7n2p209> Acesso em: 12 fev. 2015.

PARZYSZ, B. Pre-service elementary teachers and the fundamental ambiguity of diagrams in geometry problem-solving. CERME 3: Third Conference of the European Society for Research in Mathematics Education, 2003 in Bellaria, Italy, 2003.Anais..., 2003. Disponível em: http://www.dm.unipi.it/ didattica/CERME3/proceedings/Groups/TG1/TG1 list.html.

PEREIRA, T. L. M. O uso do software geogebra em uma escola pública: interações entre alunos e professor em atividades e tarefas de geometria para o ensino fundamental e médio. 
Dissertação de Mestrado em Educação Matemática, Universidade Federal de Juiz de Fora, 2012.

PITTALIS, M.; CHRISTOW, C. Types of reasoning in 3D geometry thinking and their relation with spatial ability. Educ. Stud. Math. 75, $191-212,2010$.

PROENÇA, M. C.; PIROLA, N. A. O conhecimento de polígonos e poliedros: uma análise do desempenho de alunos do ensino médio em exemplos e não-exemplos. Ciência \& Educação. 17, 1, 199 - 217, 2011. Disponível em $:<$ http://www.scielo.br/scielo.php?pid=S151673132011000100013\&script $=$ sci abstract\&tlng=pt $>$. Acesso em: 10 fev. 2015.

VIEIRA, M. J. P. S. M. O estudo de Pavimentações Regulares e Semi-Regulares com Ambientes de Geometria Dinâmica. Dissertação de Mestrado. Universidade Nova de Lisboa. Lisboa (Portugal), 2010.

STORMOWSKI, V.; GRAVINA, M. A.; LIMA, J. V. Tecnologia na aula de Matemática: a importância do potencial semiótico. RENOTE. Revista Novas Tecnologias na Educação, v. 11, p. 01-10, 2013. Disponível em: < http://seer.ufrgs.br/index.php/renote/article/view/44439> Acesso em: 12 fev. 2015.

TORREGROSA, G.; QUESADA, H. Coordinación de procesos cognitivos em geometria. Revista Latinoamericana de Investigacion em Matematica Educativa, v. 10, p. 275-300, 2007. Disponível em: $\quad<\quad$ http://www.scielo.org.mx/scielo.php?pid=S1665$24362007000200005 \&$ script $=$ sci arttext $>$. Acesso em: 12 fev. 2015.

USISKIN, Z. Resolvendo os dilemas permanentes da geometria escolar. . In: LINDQUIST, M.M.; SHULTE, A.P.(orgs). Aprendendo e ensinando geometria. Trad. De Hygino H. Domingues. São Paulo: Atual, 1994.

ZUIN, E. S. L. Da régua e do compasso: as construções geométricas como um saber escolar no Brasil. Dissertação de Mestrado em Educação. Universidade Federal de Minas Gerais 2001. 